\title{
THE SOCIAL LIFE OF RIVERS- ASSESSING CORRELATIONS BETWEEN SOCIETAL STABILITY AND RIVER HEALTH
}

\author{
Suhani Shah \\ G.D. Goenka Public School \\ DOI: 10.46609/IJSSER.2020.v05i03.017 URL: https://doi.org/10.46609/IJSSER.2020.v05i03.017
}

\begin{abstract}
It is well known that there is a significant relationship and correlation between the health of a river and the health of the society that has been constructed around it. Historically, people established settlements around rivers for farming and travel. With the advent of industrialization and technological change, there have been varied uses for rivers and water bodies. In many places around the world, there is also a deep cultural significant attached to the main river around which a city is constructed. This paper will examine the various facets and indicators for the assessment of both river health and societal stability, and the correlation between the two. The paper will then argue that policies must be framed in such a way that both these goals should not be viewed in isolation but can rather only be achieved if they are approached in parallel fashion, using the case study of the city of Varanasi. The paper will conclude by posing recommendations for better integration and communication between the scientific and political community, as well as civil society.
\end{abstract}

Keywords: Health of rivers, Quality of water, Environment, Health, Society

\section{INTRODUCTION}

Since the first human beings started to live sedentary lifestyle, the rivers have had significant role in the life of people and in the development of the settlement. The main functions of the river were: protection, crafts related with water and maintenance of industrial enterprises. Therefore, the shape of the city that time highly depended on the river (Maciukenaite, 2013). With increased industrialization and technological changes, the health of rivers has come to be assessed in different ways, and the meaning of river health is different for different stakeholders. 


\section{International Journal of Social Science and Economic Research}

ISSN: $2455-8834$

Volume: 05, Issue: 03 "March 2020"

To irrigators, rivers are healthy if there is enough water for their fields. For a power utility, rivers are healthy if there is enough water to turn the turbines. For a drinking-water utility, rivers are healthy if there is enough pure, or purifiable, water throughout the year (Karr, 1999). To sport or commercial fishers, rivers are healthy if there are fin-fish and shellfish to harvest. For recreationists, rivers are healthy if swimming, water skiing, or boating do not make people ill (Karr, 1999).

Given the importance of water sources and the looming threat of climate change and scarcity of water, it is crucial to begin to address river health and the subsequent impact on cities, in a more cohesive manner. This paper will examine the correlation between the health of rivers and societal health and examine case studies of the influence that a society has on a river and vice versa. The paper will then pose recommendations on ways to improve the health of society and rivers together, to increase sustainability in times of environmental damage.

\section{BACKGROUND}

Traditionally, the health of a river has been associated with the water quality of the river. It has been based solely on the measurement of physical, chemical and some biological characteristics. However, a criticism of this traditional approach is that while it may be useful for regulating effluent discharges and protecting humans from pollution, it is not very useful for large scale management of catchments or for assessing whether river ecosystems are truly being protected (Norris and Thoms, 1999).

Measurements of aquatic biota, to identify structural or functional integrity of ecosystems, have recently gained acceptance for river assessment. Empirical evidence from studies of river ecosystems suggest that a small group of biological ecosystem-level indicators can assess river conditions (Norris and Thoms, 1999). However, physical and chemical features of the environment affect these indicators, the structure and function of which may be changed by human activities. Often, the term river health is seen as analogous to human health (Norris and Thoms, 1999). However, the definition of river health continues to remain obscure, ambiguous, and disputed. Therefore, it has been suggested that an increased examination of relationships between environmental variables that affect aquatic biota such as habitat structure, flow regime, energy sources, water quality and biotic interactions and biological condition, are required in the study of river health (Norris and Thoms, 1999).

Traditionally, the health of society has been measured through economic indicators such as Gross Domestic Product, Gross National Product, unemployment indicators, etc. However, there are countries such as Bhutan which are moving away from traditional economic indicators and 


\section{International Journal of Social Science and Economic Research}

ISSN: $2455-8834$

Volume: 05, Issue: 03 "March 2020"

instead measuring human and societal health using happiness as an indicator (GNH Center, Bhutan).

A continuous evaluation of the definitions of both river and societal health needs to be undertaken to examine the correlation between the two in a more holistic and comprehensive manner. It has been argued that we can define health and integrity in ways that will operationalize the terms, using them to help us understand humans' relationship with their surroundings (Karr, 1999). The term 'integrity' applies to the condition of places at one end of a continuum of human influence: those that support a biota that is the product of evolutionary and biogeographic processes with minimal influence from modern human society (Karr, 1999).

\section{DISCUSSION}

Historically, the most important longitudinal connectivity function of rivers was their role as major transport routes and the simplification of formerly complex, irregular banks and beds, into straight, uniform shipping channels has resulted in a loss of lateral and vertical connectivity, notably the quotidian uses such as fishing, washing clothes, water supply, swimming and other recreation (Kondolf and Pinto, 2017). Now, rivers all over the world are under severe threat due to technological advancement. The 'World Watch Reader' reports: 'The Nile, the Ganges, Amu Dar'ya and Syr Dar'ya, the Yellow River and the Colorado are each now so dammed, diverted, or overtapped that, for parts of the year, little or none of their freshwater reached the sea (Kumar et al, 2012). Their collective diminution portends not only worsening water shortages and potential conflicts over scarce supplies, but mounting the ecological damage'. As a result, increasing number of water-borne diseases is spreading among the people who live along the banks of such polluted rivers (Kumar et al, 2012). As per WHO estimates, 1.1 billion people lack access to an improved drinking water supply; many more drink water that is grossly contaminated (Kumar et al, 2012).

However, industrialization and effluent release is not the only issue facing the health of rivers. As argued in the above sections, it is important to see the involvement of the society around the river in a more holistic manner than just economic and biological factors. Only then can any definitions or correlations between river health and societal health be holistic.

The city of Varanasi is a prime example for a case study in this regard. While Varanasi is a booming center of commerce and industry, the societal values and myths surrounding the Ganga river has also led to the long term damage of the water body and declining river and societal health. Varanasi is one of the oldest cities in Asia situated on the left bank of the River Ganga along the seven kilometre-long river face extending from Rivers Assi in the south to Varuna in the north. According to Hindu mythology, Varanasi city, also known as Kashi, is described as a 


\section{International Journal of Social Science and Economic Research}

ISSN: $2455-8834$

Volume: 05, Issue: 03 "March 2020"

column of light and as the Headquarters of Lord Shiva. Needless to say, that both the River Ganga and Varanasi city are very important and symbol (Kumar et al, 2012; Basak et al, 2015).

Due to rapid growth of population, construction of settlements along and on the low-level lands along the rivers Assi and Varuna has caused severe detrimental effects on those rivers. Assi river is now nothing more than a drain through which only the sewage from the city flows and enters into the river Ganga (Kumar et al, 2012; Basak et al, 2015). Many plans for cleansing of River Ganga, cleaning of the city, development of the city etc. were and are made but due to political pressures, they are sometimes suspended, discarded or are changed because of which they are unable to achieve their objectives. In the year 1986, the Government of India passed Ganga Action Plan (GAP), the objective of which was to reduce or remove the pollution of the River Ganga by putting up more treatment plants and better sewage system so as to avoid dumping of untreated raw sewage directly into the river (Kumar et al, 2012; Basak et al, 2015).

Even after the completion of Phase I of the GAP in the year 1993, the river water quality did not show considerable change. In the last 50 years, Varanasi has undergone very haphazard and unplanned growth. Solid waste disposal is also a big problem in the city since there is absence of any good system for it. Because of this, a lot of solid waste is either thrown in the river or it flows down in the sewage lines and/or open drains and gets dumped in the river via around 30 such point sources located along the ghats in the city (Kumar et al, 2012).

Studies show that the quality of water in the river has gone down considerably. The major reason for this is rapid and haphazard growth of the urban area of the city and big growth in total population as well as population density in the central parts of the city. The water supply and sanitation facilities of the city are unable to cope up with the very high rate of unregulated growth which has made correction of situation very difficult. All the plans working for better water supply facilities, waste disposal system, cleaning up of the river etc. are either too weak or are not planned according to the unique conditions present in the city (Kumar et al, 2012).

Because of very old water distribution system and sewage pipe lines and lack of maintenance, most of the water supplied in most parts of the city is polluted with the sewage materials leaking from sewer lines. Water is supplied in the morning and in the evening times throughout the city, and whenever the water supply starts, a lot of very dirty, smelly water comes for the first few minutes. After that the water looks clean enough to be used. But even then it contains small quantities of the sewage materials, which is continuously being leaked into the distribution supply system (Kumar et al, 2012).

Because of this, water-borne diseases are way too common in many parts of the city. People who cannot afford costly water purifying systems are forced to drink the supplied water directly 


\section{International Journal of Social Science and Economic Research}

ISSN: $2455-8834$

Volume: 05, Issue: 03 "March 2020"

which causes severe health problems. As of data available in 2006, The overall rate of waterborne/enteric disease incidence, including acute gastrointestinal disease, cholera, dysentery, hepatitis-A, and typhoid, was estimated to be about $66 \%$ during the one-year period prior to the survey. analysis revealed significant associations between water-borne/enteric disease occurrence and the use of the river for bathing, laundry, washing eating utensils, and brushing teeth (Hammer and Tripathi, 2006). Thirty-three cases of cholera were identified among families exposed to washing clothing or bathing in the Ganges while no cholera cases occurred in unexposed families (Hammer and Tripathi, 2006). Other exposure factors such as lack of sewerage and toilets at residence, children defecating outdoors, poor sanitation, low income and low education levels also showed significant associations with enteric disease outcome (Hammer and Tripathi, 2006). Such problems due to unsanitary water are also observed in other major cities in the world, such as Cairo, due to the pollution of the Nile River.

The River Ecosystem Health (REH) Concept has shown some traction and progress in how the correlation between river and societal health is viewed. Besides having a unique meaning, the REH metaphor has added value to river management by being able to mobilize scientists, practitioners and publics and seeing relationships at the level of values. It places humans at the centre of the river ecosystem, while seeking to ensure the durability of the ecosystem of which they are an integral part (Vugteveen, 2006).

\section{CONCLUSION}

The case study of Varanasi and the situation in different parts of the world shows that improve river and societal health, there needs to be an integrated approach which does not view either the river or the city around it in isolation. Both goals need to be achieved in a parallel manner, taking into account not only empirical data but also the societal values and group attitudes that have emerged around a river. For example, in Varanasi, continuously worsening quality of water of the Ganga river shows that the various government plans to cleanse the river has failed and is still failing to do their job. Until the objective of cleaning the Ganga is achieved, people should be educated and informed about the situation of the river quality so that the use of its water for daily purposes is stopped. Alternate clean water resources for people living in the slums are to be provided. Only with this integrated approach that also focuses on the society itself, can both river health and societal health be achieved effectively (Kumar et al, 2012; Basak et al, 2015).

Communicating the condition of biological systems, and the consequences of human activities for those systems, is the ultimate purpose of biological monitoring. Effective communication can transform biological monitoring from a scientific exercise into an effective tool for environmental decision making. Politics plays an enormous role in environmental policy 
International Journal of Social Science and Economic Research

ISSN: $2455-8834$

Volume: 05, Issue: 03 "March 2020"

decisions. Scientists cannot hope to affect those decisions if they cannot communicate effectively to the decision makers (Karr, 1999).

With available statistics and indices that explain biological condition in numbers and words, biologists can make use of what they know, now. By talking and writing well beyond the confines of academic journals, they can root out the call for more research and call instead for widespread understanding of condition and trends in river health. This will also help the general public understand the importance of river health and will aid in mobilizing volunteer support, among other effective public activities (Karr, 1999).

\section{REFERENCES}

Basak, S., (September 2015), 'Ghats of Varanasi - An Emerging Centre of Pollution', IOSR Journal Of Humanities And Social Science, Volume 20, Issue 9, PP 19-24

GNH Happiness Center, Bhutan, 'GNH Happiness Index', available at: http://www.gnhcentrebhutan.org/what-is-gnh/gnh-happiness-index/

Hammer, S., and Tripathi, A., (May 2006), 'The role of water use patterns and sewage pollution in incidence of water-borne/enteric diseases along the Ganges River in Varanasi, India', International Journal of Environmental Health Research 16(2):113-32

Karr, J., (1999), 'Defining and Measuring River Health', Freshwater Biology, Vol.41, 221-234

Kondolf, G., and Pinto, P., (2017), 'The social connective of urban rivers', Geomorphology, Vol. 277, pp 182-196

Kumar S., et al, (2012), 'Pollution of Ganga River Due to Urbanization of Varanasi: Adverse Conditions Faced by the Slum Population', Environment and Urbanization Asia, Vol. $3(2), 343-352$

Maciukenaite, J., (2013) 'The Role of the River in the City Centre and its Identity', Journal of Sustainable Architecture and Civil Engineering, Vol. 4

Norris, R., and Thoms, M., (1999), 'What is River Health?', Freshwater Biology, Vol. 41, 197209

Vugteveen, P., et al, (2006) 'Redefinition and elaboration of river ecosystem health: perspective for river management', In: Leuven R.S.E.W., Ragas A.M.J., Smits A.J.M., van der Velde 
International Journal of Social Science and Economic Research

ISSN: $2455-8834$

Volume: 05, Issue: 03 "March 2020"

G. (eds) Living Rivers: Trends and Challenges in Science and Management. Developments in Hydrobiology, vol 187. Springer, Dordrecht 